(2) (1) https://creativecommons.org/licenses/by/4.0/

\title{
ARTIGO \\ HABITUS E DECOLONIALIDADE: POLÍTICAS DE COTAS NO ACESSO AO ENSINO SUPERIOR PARA DESCONSTRUÇÃO DO IMAGINÁRIO COLONIAL
}

\author{
RENATA ANDRADE DE LIMA E SOUZA ${ }^{1}$ \\ ORCID: https://orcid.org/0000-0002-8418-1915 \\ JAQUELINE MOLL² \\ ORCID: https://orcid.org/0000-0001-5465-178x \\ FÁBIO BEZERRA DE ANDRADE ${ }^{3}$ \\ ORCID https://orcid.org/0000-0003-2741-7490
}

\begin{abstract}
RESUMO: Este texto constitui parte da pesquisa que analisa o perfil dos estudantes egressos de escolas públicas que ingressaram na Universidade Federal Rural de Pernambuco por intermédio da política de cotas. O objetivo é apresentar, a partir de relatos coletados através de entrevistas, esses estudantes recém-ingressantes nos dois cursos mais concorridos em 2018, seus desafios para o letramento acadêmico, que é influenciado pelo habitus, na sua trajetória escolar e as perspectivas desses jovens para a diplomação. Para tanto, seguimos uma abordagem qualitativa e realizamos uma discussão teórica sobre os conceitos de habitus, pensando na sua constituição a partir de um imaginário colonial que a política de cotas contribui para desestruturar.
\end{abstract}

Palavras-chave: política de cotas, universidade, ensino superior, habitus.

\section{HABITUS AND DECOLONIALITY: QUOTA POLICIES ONACCESS TO HIGHER EDUCATION FOR DECONSTRUCTION OF THE COLONIAL IMAGINARY}

\begin{abstract}
This text is part of the research that analyzes the profile of public school students who entered the Federal Rural University of Pernambuco through the Quotas Policy. The objective is to present, from reports collected through interviews, how these newly enrolled students in the two most competitive courses in 2018 present the challenges for academic literacy, which is influenced by the habitus, in its school trajectory and the perspectives of these young people for the diploma. In order to do so, we follow a qualitative approach and carry out a theoretical discussion about the concepts of habitus, thinking that this is constituted from a colonial imagery that the dimension politics contributes to de-structuring.
\end{abstract}

Keywords: Quotas Policy, University, Higher Education.

\footnotetext{
${ }^{1}$ Universidade Federal do Rio Grande do Sul (UFRGS). Porto Alegre, RS, Brasil. <natadelima@yahoo.com.br>

${ }^{2}$ Universidade Federal do Rio Grande do Sul (UFRGS). Porto Alegre, RS, Brasil. < jaquelinemoll@gmail.com >

${ }^{3}$ Universidade Federal Rural de Pernambuco (UFRPE). Recife, PE, Brasil. <fabiobandrade@yahoo.com.br > Educação em Revista|Belo Horizonte|v.36|e225572|2020
} 


\section{HABITUS Y DECOLONIALIDAD: POLÍTICAS DE CUOTAS DEEL ACCESO A LA ENSEÑANZA SUPERIOR PARA DECONSTRUCCIÓN DEL IMAGINARIO COLONIAL}

RESÚMEN: Este texto forma parte de la investigación que analiza el perfil de los estudiantes egresadosde escuelas públicas que ingresaron en la Universidad Federal Rural de Pernambuco por intermedio de la Política de Cuotas. El objetivo es presentar, a partir de relatos recolectados por intermedio de entrevistas, como esos estudiantes recién ingresados en los dos cursos más concurridos en 2018, presentan los desafíos para el literal académico, que es influenciado por el habitus, en su trayectoria escolar y las perspectivas de estos jóvenes para la diplomación. Para ello, seguimos un abordaje cualitativo y realizamos una discusión teórica sobre los conceptos de habitus, pensando que éste se constituye a partir de un imaginario colonial que la política de cuotas contribuye a desestructurar.

Palabras clave: Política de Cuotas, Universidad, Enseñanza Superior. 


\title{
INTRODUÇÃO
}

Como o ingresso em uma universidade pública federal influencia o babitus de um estudante cotista? A resposta a essa pergunta desencadeou esta investigação, realizada com estudantes egressos de escola pública que ingressaram na Universidade Federal Rural de Pernambuco-UFRPE.

Aqui pretendemos realizar uma discussão teórica acerca da ordem social que se reafirma no sistema escolar, em que o capital cultural pode ser um dos fatores determinantes para o sucesso e o fracasso na vida escolar, ao mesmo tempo em que o sistema de cotas desestabiliza essa lógica.

Este texto apresenta o resultado de parte da pesquisa de Doutorado em Educação, cadastrada no Comitê de Ética em Pesquisa (Coep) sob o número 070573/2019, realizada com estudantes cotistas dos dois cursos mais concorridos da UFRPE no ano de 2018. A coleta foi por meio de entrevistas, no intuito de observar como esses estudantes recém-ingressantes passam a conviver com códigos próprios da academia e como essa relação é influenciada e influencia o seu habitus, colocandolhes limites e desafios para o letramento acadêmico.

Belletati (2011) afirma que muito se questionou sobre o potencial dos estudantes egressos de escolas públicas, acreditando que eles, em geral, são socioeconomicamente menos favorecidos e apresentam algumas lacunas de habilidades e conteúdos básicos, reafirmando um sistema escolar que, no âmbito da sociedade brasileira, é pensado a partir de um imaginário colonial, imposto pela modernidade e que influenciará diretamente a constituição do habitus desses estudantes cotistas. ${ }^{4}$

$\mathrm{Na}$ perspectiva da produção de conhecimento, esses estudantes cotistas não irão apenas construir saberes necessários para a conclusão do seu curso, mas conviverão com a escrita, a oralidade e com as práticas sociais típicas da universidade, que se somará a seu capital cultural. O capital cultural, segundo Bourdieu (2008), representa a herança cultural do indivíduo, na forma de conhecimentos apreendidos durante a sua trajetória de vida. E a herança cultural aproxima ou distancia os sujeitos da universidade.

\begin{abstract}
A maior importância do capital cultural é de servir como uma ponte entre os conhecimentos ministrados na escola e os conhecimentos adquiridos em casa. O aprendizado é muito mais simples para aqueles indivíduos que possuem uma família que faz uso dos códigos socialmente legítimos. A instituição escolar consagra e transmite determinados saberes que são desigualmente distribuídos entre os grupos sociais. Logo, a posse de certo patrimônio cultural e de um ethos familiar predisposto a valorizar e incentivar a cultura escolar seriam elementos importantes para alcançar o sucesso acadêmico. (NOVAES; VARGAS, 2015. p. 327)
\end{abstract}

De acordo com Bourdieu (2008), o destino escolar diz respeito ao sistema de valores internalizados pelo indivíduo a partir da posição social ocupada pelo grupo familiar. Tais valores irão configurar seu capital cultural.

Assim, o que se pretende é identificar o habitus dos estudantes oriundos de escolas públicas que ingressaram na universidade pública federal por intermédio das políticas de ações afirmativas, para, então, perceber o habitus como influência desse novo contexto.

Para tanto, iremos iniciar com a abordagem do conceito bourdieusiano de habitus, para situar como ele poderá respaldar os estudos sobre a política pública de acesso ao ensino superior. Partese do princípio de que essa política pode influenciar e alterar a vida dos indivíduos e seu habitus, a partir das dificuldades e superações no espaço acadêmico.

Segundo Bourdieu (1999), a família é o principal espaço para a construção do habitus, porém, é na escola que se perpetuam as relações sociais e se constitui, a partir do capital cultural, o princípio da eliminação diferencial das crianças das distintas classes sociais, ao mesmo tempo em que a educação é associada às possibilidades de mudança social (MELO; CAMPOS; ZARIAS, 2015).

Como nos apresentam Nogueira e Nogueira (2002, p. 20), a tese bourdesiana aponta que

${ }^{4}$ A Lei n. 12.712/2012 estabeleceu cota de 50\% das vagas destinadas aos cursos de graduação nas universidades federais brasileiras para serem preenchidas, anualmente, por estudantes oriundos de escolas públicas. Assim, a Lei ficou conhecida como a Lei das Cotas. 
a partir de sua formação inicial em um ambiente social e familiar que corresponde a uma posição específica na estrutura social, os indivíduos incorporariam um conjunto de disposições para a ação típica dessa posição (um habitus familiar ou de classe) e que passaria a conduzi-los ao longo do tempo e nos mais variados ambientes de ação.

De acordo com Bourdieu (1999), a sociedade organiza-se para fixar um consenso que se constitui por uma lógica que permite à cultura dominante cumprir sua função político-ideológica de legitimar e sancionar um determinado regime de dominação. Esse pensamento, aplicado ao sistema acadêmico que sempre predominou no Brasil, fez com que a exclusão de grande parte da sociedade do ensino superior fosse vista como natural, como um fenômeno que podia ser explicado na visão meritocrática de mundo.

Possibilitar o ingresso desse grupo, até então excluído, por via de políticas públicas, é romper um sistema "lógico" simbólico. Essa ruptura não pode ser pensada apenas do ponto de vista da coletividade, apesar de ser a sua maior expressão. Ela ocorre primeiro no próprio indivíduo ou, como diria Bourdieu (1999), expressa-se no seu habitus, sendo esse o princípio operador que leva a cabo a interação entre dois sistemas de relações, as estruturas objetivas e práticas, isto é, essa relação do indivíduo com as estruturas exteriores a partir dos sistemas de disposições incorporadas por ele. Assim, a relação do estudante com esse novo espaço será, em grande parte, fruto do babitus que, apesar de estar constituído, está em constante constituição.

O objetivo geral é discutir como o sistema escolar reafirma a ordem social a partir dos conceitos de habitus, campo e capital cultural, identificando no campo acadêmico o habitus desses estudantes e suas influências em relação a trajetórias de vida marcadas pelo imaginário colonial. Como objetivos específicos, buscamos: a) discutir a democratização do acesso ao ensino superior como possibilidade de mudança social desses estudantes e como o habitus, influenciado pelo imaginário colonial, influencia suas trajetórias acadêmicas; b) discutir, a partir da perspectiva decolonial, a importância da política de cotas para desestruturar a lógica do sistema educacional; c) discutir como o babitus tem reflexo na sua trajetória acadêmica e se manifesta no letramento desses estudantes.

Para tanto, discutiremos a abordagem de Bourdieu, considerando também os conceitos do movimento decolonial ${ }^{5}$, que compreende a construção dos indivíduos a partir de um imaginário social que naturaliza uma sociedade marcada pela exclusão social de determinados grupos, mas que encontra na política de cotas uma possibilidade de mudança e de desconstrução do imaginário colonial no campo da educação.

\section{O HABITUS E A (DES)CONSTRUÇÃO DO IMAGINÁRIO COLONIAL A PARTIR DA POLÍTICA DE COTAS}

O conceito de habitus aponta que "as estratégias desenvolvidas pelos sujeitos marcam símbolos distintos dos mesmos e aproximam realidades vividas" (PINHEIRO, 2011, p.32). Ele é um produto da história pessoal e coletiva que funciona colocando o sujeito como agente social transformador e em transformação. Portanto, é importante lembrar que os agentes têm história, "que são produto de uma história individual, de uma educação associada a determinado meio, além de serem o produto de uma história coletiva" (BOURDIEU; CHARTIER, 2011, p. 58).

Para Bourdieu e Passeron (1992, p. 21), a escola é uma instituição que reproduz a cultura dominante e contribui para reproduzir a estrutura das relações de força, numa formação social onde $\mathrm{o}$ sistema de ensino dominante tende a assegurar-se do monopólio da violência simbólica.

Ao possibilitar uma maior abertura para a fração da população de nível de renda baixa, para quem era inviável o ensino pago, produzimos um impacto social, afirmam Melo, Campos e Zarias

\footnotetext{
${ }^{5}$ Grupo de intelectuais latino-americanos constituído no final dos anos 1990, que tem por objetivo estudar e expor as marcas deixadas pela colonização/colonialidade europeia na América Latina, nas instituições, na racionalidade científica e nas hierarquias sociais e raciais como processos indissociáveis da modernidade.
} 
(2015), que altera o habitus de origem dos jovens de classes excluídas, incorporando novos capitais à sua trajetória.

O acesso a um universo que até pouco tempo era exclusivo para poucos, permite que as experiências vividas no âmbito da universidade possam se sobrepor aos estratos de disposições anteriores e isso é agregado ao seu capital cultural. O estudante vai adquirir esse capital cultural acadêmico a partir das práticas sociais próprias da academia.

Como afirmam Melo, Campos e Zarias, o sucesso na trajetória acadêmica muitas vezes está relacionado ao acesso ao ensino superior e o diploma tem um valor simbólico "capaz de promover a diferenciação social" (MELO; CAMPOS; ZARIAS, 2015, p. 6). Além do mais, entrar em uma universidade possibilita criar condições para que se manifeste o gosto pelo ensino superior pois:

Dar acesso aos que vinham sendo historicamente excluídos - e cuja exclusão estava
incorporada pelos próprios excluídos - exige uma mudança no processo de escolarização, no
qual professores de ensino fundamental e médio têm que incorporar o ideal de superação de
um habitus internalizado sobre as condições de existência dos jovens de periferia e do interior
oriundos de escolas públicas. (MELO; CAMPOS; ZARIAS, 2015, p. 6)

Assim como não é tarefa fácil o ingresso, também não é fácil a trajetória acadêmica desses estudantes. Na concepção de Bourdieu (2008), o processo de formação do indivíduo é produto da acumulação do capital cultural herdado da família. Assim, o capital cultural pode determinar o fracasso ou o sucesso escolar. Logo, afirmam Melo, Campos e Zarias (2015), a ausência ou fragilidade de capital cultural pode favorecer o fracasso na trajetória escolar para jovens de famílias não detentoras desse capital.

Souza (2012) afirma que o sistema de ensino brasileiro ignora a origem dos estudantes, transmitindo um ensino padrão. Esse processo é definido por Bourdieu e Passeron como ação pedagógica que "perpetua a violência simbólica através de duas dimensões arbitrárias: o conteúdo da mensagem transmitida e o poder que instaura a relação pedagógica exercido por autoritarismo" (SOUZA, 2012, p. 27). E conclui: "O dominado não se opõe ao seu opressor, já que não se percebe como vítima deste processo, ao contrário, o oprimido considera a situação natural e inevitável" (SOUZA, 2012, p. 27).

Para os filhos das classes trabalhadoras, a escola representa uma ruptura no que refere aos
valores e saberes de sua prática, que são desprezados, ignorados e desconstruídos na sua
inserção cultural, ou seja, necessitam aprender novos padrões ou modelos de cultura. Sendo
assim, para os alunos filhos das classes dominantes alcançarem o sucesso escolar torna-se bem
mais fácil do que para aqueles que têm que desaprender uma cultura para aprender um novo
jeito de pensar, falar, movimentar-se, enfim, enxergar o mundo, inserir neste processo para se
tornar um sujeito ativo nesta sociedade. (SOUZA, 2012, p. 29)

Para Bourdieu (1999), o capital cultural acumulado favorece o desempenho escolar na medida em que o indivíduo está familiarizado com os códigos e conteúdos escolares, uma vez que o sistema escolar produz e confirma os significados desses códigos produzidos pela classe dominante e legitimados na escola.

A cultura (neste caso a escolar) produz um mundo social que se ajusta à estrutura das relações sociais e econômicas, que passa a ser vista como natural e passa a contribuir para a conservação simbólica das relações de forças vigentes (BOURDIEU, 1999, p. 12).

Nessa perspectiva, os estudantes oriundos das classes dominantes têm maiores possibilidades em relação ao sucesso escolar do que os estudantes oriundos das classes dominadas, que precisam aprender novos padrões culturais para se inserir em espaços valorizados socialmente.

Esses sujeitos possuem um habitus cultivado e, além disso, a escola é uma força formadora de hábitos, pois é nela que os sujeitos se encontram, direta ou indiretamente, submetidos à influência de diferentes campos de pensamento e ação, que são transmitidos por uma cultura dominante. 
A política de cotas nas universidades é oriunda da tentativa de romper a exclusão social baseada no mérito pessoal, afirma Castro (2014), já que o mérito se revela como uma sorte que se pode ter ou não, mas nunca é oferecido a todos.

Nesse sentido, faz-se necessário pensar formas que rompam o ideal de mérito como a única forma de acesso à educação, promovendo mudanças significativas na ordem social para enfrentar as distâncias sociais dos grupos excluídos, conforme apontam Melo, Campos e Zarias (2015), e romper com essa ordem social é romper com o imaginário colonial constituído a partir do processo colonizador.

A internalização da exclusão pelos próprios excluídos foi predisposta historicamente a partir do que Aníbal Quijano denomina "colonialidade do poder" " pela qual colonizadores europeus estabeleceram uma relação de poder baseada na superioridade étnica e cognitiva dos colonizadores sobre os colonizados" (apud CASTRO-GOMEZ, 2005, p. 62). Isso significa dizer que a dominação não se deu apenas econômica, política e militarmente, mas ocorreu pela dominação dos modos de conhecer, de produzir conhecimento e por naturalizar a cultura europeia como a única forma de se relacionar com a natureza, o mundo social e com a subjetividade, eliminando as muitas outras formas de conhecimento dos povos colonizados.

Os colonizadores reprimiram os padrões de produção de sentidos, o universo simbólico, os padrões de expressão e de objetivação da subjetividade dos povos colonizados. Para eles, os nãoeuropeus eram vistos como constituintes de uma subcultura, iletrados e desprovidos de herança intelectual, como afirma Quijano (2005).

A negação do outro deprecia a diversidade dos povos colonizados e determina o etnocentrismo europeu, o que leva ao encobrimento do outro não europeu. Assim, às populações dominadas foi imposta uma relação de superioridade/inferioridade e estabelecida uma hegemonia europeia que definia "todas as formas de controle da subjetividade, da cultura, e em especial do conhecimento, da produção do conhecimento" (QUIJANO, 2005, p. 121), estabelecendo a colonialidade do poder.

Um dos eixos fundamentais do padrão de poder eurocentrado é a classificação social da população mundial de acordo com a ideia de raça, "uma construção mental que expressa a experiência básica da dominação colonial e que desde então permeia as dimensões mais importantes do poder mundial, incluindo sua racionalidade específica" (QUIJANO, 2005. p. 117). Esse eixo, conforme nos apresenta Quijano, é de origem e caráter colonial, porém mais duradouro e estável do que a matriz que lhe constituiu. Assim, a América foi construída como a primeira identidade da modernidade, constituindo-se "como o primeiro espaço/tempo de um padrão de poder de vocação mundial" (QUIJANO, 2005, p.117).

A raça foi um dos principais e primeiros critérios para a classificação da população mundial e ela ocupa lugar na estrutura de poder da sociedade, onde os povos colonizados foram desprovidos de suas singularidades, de suas identidades históricas, passando a constituir uma "nova identidade racial, colonial e negativa [...] implicava o despojo de seu lugar na história da produção cultural da humanidade" (QUIJANO, 2005, p. 127).

O fenômeno do poder é caracterizado como um tipo de relação social constituído pela copresença permanente de três elementos - dominação, exploração e conflito -, afirma Quijano (2002), e o atual padrão de poder mundial consiste na articulação entre:

a colonialidade do poder, isto é, a idéia de "raça" como fundamento do padrão universal de classificação social básica e de dominação social; 2) o capitalismo, como padrão universal de

\footnotetext{
${ }^{6}$ Colonialidade do poder é um conceito que dá conta de um dos elementos fundantes do atual padrão de poder: a classificação social básica e universal da população do planeta em torno da ideia de "raça". Essa ideia e a classificação social e baseada nela (ou "racista") foram originadas há 500 anos junto com a América, a Europa e o capitalismo. São as mais profundas e perduráveis expressões da dominação colonial e foram impostas sobre toda a população do planeta no curso da expansão do colonialismo europeu. Desde então, no atual padrão mundial de poder, impregnam todas e cada uma das áreas de existência social e constituem a mais profunda e eficaz forma de dominação social, material e intersubjetiva. Por isso mesmo, são a base intersubjetiva mais universal de dominação política dentro do atual padrão de poder (QUIJANO, 2002, p.04).
} 
exploração social; 3) o Estado como forma central universal de controle da autoridade coletiva e o moderno Estado-nação como sua variante hegemônica; 4) o eurocentrismo como forma hegemônica de controle da subjetividade/ intersubjetividade, em particular no modo de produzir conhecimento (QUIJANO, 2002, p.04).

A ideia de raça vai ganhando conotações além da subjetividade da cor da pele, é o que discute Castro-Gomez, na obra La hybris del punto cero: ciencia, raza e ilustración en la Nueva Granada (2005), onde o discurso do "ser branco" dos "criollos de Nueva Granada", com base na ideia da limpeza de sangue, é acercada à transmissão por hereditariedade do ser nobre, do "direito" de ser reconhecido como elite a partir da rede de parentesco e aquisição de títulos de nobreza, distinguindo os níveis de vida entre ricos e pobres.

Essa autodenominada "elite", pesquisada por Castro-Gomez (2005), construiu um "imaginário cultural de brancura" que pouco tem a ver como a cor da pele, mas com o tipo de riqueza e distinção social "la blancura era, pues, primordialmente un estilo de vida demonstrado públicamente por los estratos más altos de la sociedad y deseado por todos los démas grupos sociales." (CASTROGOMEZ, 2005, p. 71).

Assim, essa elite distinguia-se pelos valores culturais, pelo seu capital cultural, tendo pouco a ver com o tipo de profissão, as atividades, o êxito econômico. Trata-se de distinções sociais como crenças religiosas, tipos de roupas, certificados de nobreza, modos de comportamento e formas de produzir conhecimento. Essa distinção faz com que o indivíduo seja identificado como pertencente a uma classe ou a outra e, nesse sentido, o conceito de classe vai muito além do conceito marxista ${ }^{7}$, tendo como base os diferentes tipos de relações de poder entre os diferentes grupos sociais. Nessa noção bourdeusiana, as diferenças de classe não podem ser explicadas unicamente pelo viés econômico, mas pela existência de diferentes esquemas de classificação das práticas sociais.

$\mathrm{O}$ indivíduo que domina certas práticas sociais pode ser considerado de uma classe ou de outra, o que se encontra muito no imaginário coletivo da ordem social, guiado para consolidar as hierarquias sociais e manter essa ordem.

Essa dimensão cognitiva do discurso da elite permite a construção de um imaginário no qual tanto uns como outros reconhecem e legitimam esta ordem social, afirma Castro-Gomez (2005), colocando cada um no seu "lugar natural" da sociedade, o que o autor denomina como "a sociologia espontânea das elites".

O discurso da limpeza de sangue da elite com toda sua conotação étnica e separatista, afirma o autor, é parte integral do habitus da elite dominante, operando como princípio de construção da realidade social (CASTRO-GOMEZ, 2005, p. 73). O habitus, então, será um fator determinante para identificar em que classe social o indivíduo pode ser inserido.

Bourdieu desenvolve a noção de habitus "para conceptualizar el modo en que los individuos incorporan en su estructura psicológica toda una serie de valores culturales pertinentes a su "condición de clase " y que le identifican, de forma indefectible, como miembro de un determinado grupo social" (CASTRO-GOMEZ, 2005, p. 81).

Assim como Castro-Gomez (2005), utilizaremos a noção de habitus, mas para identificar o sujeito, estudante de escola pública que ingressa na universidade por intermédio das cotas de ações afirmativas, e a (re)construção de sua realidade e sua subjetividade no espaço acadêmico.

Quando ocorre a seleção e exclusão de um grupo ou de uma classe, com base nas relações de forças ocultadas e dissimuladas, estamos diante de uma violência simbólica, que é dissimulada pelo poder arbitrário, que faz com que o educando naturalize essa exclusão e a torne durável, processo que Bourdieu e Passeron (1992) definem como o arbitrário cultural.

\footnotetext{
${ }^{7} \mathrm{Na}$ concepção marxista, as classes, numa sociedade capitalista, surgem a partir da divisão social do trabalho e são fundamentalmente duas: a burguesia, composta pelos proprietários dos meios de produção; e o proletariado, composto por aqueles que vendem sua força de trabalho por não disporem de meios de produção (BOBBIO; MATTEUCCI; PASQUINO, 2010). Cada classe, burguesia (classe dominante) e proletariado (classe dominada), coloca os agentes sociais nas mesmas condições no processo de produção e com as mesmas afinidades ideológicas e políticas.
} 
Assim, o sistema de ensino reproduz e perpetua a distinção, conservando uma ordem social alicerçada no valor simbólico da distinção social, como, por exemplo, a raridade dos títulos defendidas pelos conservadores desse sistema que, segundo os autores, sob a aparência de defender o valor desses títulos, defendem a existência de um mercado simbólico, com as funções conservadoras que ele assegura (BOURDIEU; PASSERON, 1992, p. 69).

Essa imposição legitima, dissimula e expressa a violência simbólica, com a interiorização da cultura dominante e sua correlação com as desigualdades sociais e do sistema escolar, onde as posições de mais prestígio tendem a ser ocupadas pelos indivíduos dos grupos dominantes socialmente.

Souza (2012, p. 21) corrobora essa perspectiva quando afirma que:

Por mais que se democratize o acesso ao ensino por meio da escola pública e gratuita, continuará existindo uma forte correlação entre as desigualdades sociais, sobretudo culturais. Essa correlação só pode ser explicada quando se considera que a escola valoriza e exige dos alunos determinadas qualidades que são desigualmente distribuídas entre as classes sociais, notadamente, o capital cultural e certa naturalidade no trato com a cultura e o saber, que apenas aqueles que foram desde a infância socializados na cultura legítima podem ter.

Quando o indivíduo da classe dominada consegue romper a lógica do sucesso e do fracasso escolar, a exemplo do seu ingresso em uma universidade pública federal, no contexto de uma política pública afirmativa, ele caminha para contrariar não apenas seu próprio destino, mas o sentido da ordem social estabelecida.

Os jovens beneficiários das cotas, portadores de determinado habitus vão conformando, subvertendo ou transformando suas estratégias diante de novas situações que requerem ações práticas. São desafiados a entender o sentido do jogo, o que se adquire pela experiência e pela participação em atividades sociais, principalmente no campo escolar, que esses jovens não têm na bagagem transmitida pela família, isto é, capital cultural incorporado, sendo este o que mais causa impacto no destino escolar. Essa bagagem herdada não é individual, mas de cada grupo social transmitida aos indivíduos na forma de habitus. (CAVALCANTE, 2015, p. 12)

Esse indivíduo não só vai se deparar com novos códigos e padrões, mas com uma possibilidade de transformar sua realidade e, por conseguinte, a sociedade, já que esse universo deixa de ser exclusivo de uma determinada classe. Contudo, não é uma tarefa fácil ingressar e permanecer em uma universidade e é nesse sentido que, na próxima seção, daremos "voz" aos que conseguiram romper essa barreira invisível da exclusão, mas enfrentarão um sistema escolar excludente.

\section{AS NOVAS VOZES SOCIAIS DA ACADEMIA}

A tese central de Bourdieu sobre o fenômeno escolar é a de que os estudantes não são indivíduos abstratos que competem em condições relativamente igualitárias na escola, mas são atores socialmente constituídos que trazem, em larga medida, incorporada, uma bagagem social e cultural diferenciada e mais ou menos rentável no mercado escolar (NOGUEIRA. NOGUEIRA, 2002, p. 18).

Para Bourdieu (1999), o indivíduo é fruto do capital acumulado durante sua trajetória de vida. Essa bagagem é transmitida pela família e acumulada no seu capital cultural, que favorece o desempenho escolar, pois facilitaria a aprendizagem dos conteúdos e códigos escolares.

As referências culturais, os conhecimentos considerados legítimos (cultos, apropriados) e o domínio maior ou menor da língua culta, trazidos de casa por certas crianças, facilitariam o aprendizado escolar na medida em que funcionariam como uma ponte entre o mundo familiar e a cultura escolar. A educação escolar, no caso das crianças oriundas de meios culturalmente favorecidos, seria uma espécie de continuação da educação familiar, enquanto para as outras crianças significaria algo estranho, distante, ou mesmo ameaçador. A posse de capital cultural favoreceria o êxito escolar, em segundo lugar, porque propiciaria um melhor desempenho nos processos formais e informais de avaliação. (NOGUEIRA; NOGUEIRA, 2002, p. 21) 
Assim, um estudante proveniente de uma classe em que seu capital cultural seja fragilizado apresentaria mais dificuldade em assimilar os códigos escolares. Já para as classes dominantes, o sistema de códigos escolares representa uma continuidade da sua cultura e, como explicam Nogueira e Nogueira (2002, p. 29), o sistema de ensino, tal como conhecemos, exige, mesmo que implicitamente, o domínio prévio de um conjunto de habilidades e referências culturais e linguísticas que apenas os membros das classes mais cultivadas possuiriam. Quanto aos professores, eles transmitiriam o conteúdo a todos os alunos da mesma forma, como se todos tivessem os mesmos instrumentos de decodificação.

A fim de compreender a trajetória desses estudantes cotistas, encontramos histórias de vida com muitos desafios, mas que foram superados a partir de um sonho de mobilidade social das famílias e de políticas públicas afirmativas e garantidoras de direitos.

Para o desenvolvimento da pesquisa, no ano de 2018, realizamos entrevistas com os estudantes cotistas que ingressaram nos dois cursos mais concorridos na seleção de 2018 da UFRPE: Ciência da Computação e Medicina Veterinária. A pesquisa envolveu nove estudantes ingressantes no primeiro e segundo semestre de 2018, no campus Dois Irmãos, na modalidade presencial. Essa escolha dos cursos justifica-se por serem os mais concorridos nos últimos exames. No curso de Ciência da Computação, dos nove cotistas, participaram cinco. No curso de Medicina Veterinária, dos cinco cotistas, participaram quatro. Para preservar a identidade dos entrevistados, atribuímos nomes fictícios.

No contexto da pesquisa, seis estudantes se identificaram como brancos, dois como pardos e um como negro. Um deles vivia com renda familiar de até $R \$ 1.000,00$, sete de $R \$ 1.001,00$ a $R \$$ 3.000,00 e um com mais de $\mathrm{R} \$ 5.000,00$. Todos moravam com os pais e eram solteiros. Três tinham idade até 17 anos e seis entre 18 e 23 anos.

Para um estudante de Ciência da Computação que participou da pesquisa, entrar em uma universidade é a possibilidade de "garantir um futuro melhor" e, mesmo seus pais não tendo completado a educação básico, "sempre incentivaram a entrar numa faculdade". Mesmo morando no interior de Pernambuco, seus pais fazem "de tudo para mantê-lo na capital". Pelo relato do estudante, os pais têm uma história de vida de muitos desafios e superações:

[...] eu sempre mudei muito de escola por conta de mudança de cidade. Por exemplo, eu nasci no Cabo (de Santo Agostinho), mas, até os dois anos de idade, eu morei em Porto de Galinhas. Meus pais vendiam caldinho na praia (risos). AîM depois dissoM a gente foi morar em Recife e eu estudei até os quatro anos na escolinha Raio de Sol. Depois a gente foi para São Paulo. Eles conseguiram um emprego lá e eu fiquei por lá até os oito anos, estudando em escola particular. Depois voltamos para Recife, passamos mais um ano aqui e sempre estudando em escola particular até eu ter dez anos. A gente foi para Caruaru, comecei a estudar na escola Santa Maria dos Anjos, fiquei lá até treze anos e fui pra uma escola pública, por opção própria, porque achava que seria melhor a educação dessa escola por ser uma escola de referência, EREM Maria Auxiliadora Liberato, uma escola muito boa, tem professores ótimos que eu tenho contato até hoje e possibilitou até eu fazer um programa de intercâmbio, no Programa Ganhe o Mundo. (José da Silva, Entrevista de Campo, 2018).

Pensando em como as políticas públicas são importantes para ampliar os horizontes dos jovens, nos deparamos com o relato acima em relação ao Programa Ganhe o Mundo. Esse Programa foi criado em 2011, pelo Governo do Estado de Pernambuco, por intermédio da Lei n. 14.512/2011, e visa ofertar aos estudantes do ensino médio da rede pública estadual cursos intensivos de língua inglesa, espanhola ou alemã no contraturno. Os melhores estudantes participantes são selecionados para realizar intercâmbio, com duração de um semestre letivo, em escolas públicas ou privadas dos países parceiros. trajetória escolar:

Essa experiência possibilitou ao estudante ampliar seus horizontes no que diz respeito à sua

[...] escolhi Ciência da Computação no intercâmbio. Eu fui numa universidade do Texas, com excursão da escola, e eles mostraram bastante essa parte de tecnologia e eu acabei ficando interessado. (José da Silva. Entrevista de Campo, 2018). 
As políticas públicas que democratizam e oportunizam a muitos vivenciar aquilo que antes seria pouco provável, incorporam novos capitais ao habitus do estudante, que alteram sua trajetória e seu projeto de vida.

Nesse mesmo sentido, encontramos o estudante de Medicina Veterinária cujos pais também não completaram a educação básica. A mãe é empregada doméstica e o pai trabalha como motorista no Grande Recife Consórcio de Transporte Metropolitano ${ }^{8}$.

Ele nos relata que, entre seus amigos do ensino médio, nenhum conseguiu acesso à universidade e muitos tiveram que entrar no mercado de trabalho para ajudar nas despesas de casa (Bruno Gomes. Entrevista de Campo, 2018).

Outro estudante de Medicina Veterinária relatou que seus pais também não completaram a educação básica e a escolha do curso ocorreu porque seu pai "queria muito fazer e nunca conseguiu e minha mãe também" (João Costa. Entrevista de Campo, 2018).

O que é muito recorrente nas falas dos entrevistados é a educação superior como possibilidade de uma mobilidade social e, consequentemente, econômica. Todos relataram não só a importância da família para alcançarem sucesso para ingresso na universidade, como sua expectativa de que o curso de graduação permita uma mudança de vida significativa para a família.

\section{O curso de graduação como possibilidade de mobilidade social e econômica}

Como discute Bourdieu (1999), a sociedade é organizada para manter a ordem social das classes dominantes e o acesso à educação superior representa, para muitos, a possibilidade de ruptura dessa lógica. Para os estudantes entrevistados, mesmo não possuindo, desde sua origem familiar, o capital cultural intrínseco a esse campo, eles vislumbram na universidade a possibilidade de acumulação desse capital que irá representar uma mudança na sua trajetória de vida e, consequentemente, será incorporado a seu habitus.

Para o estudante de Ciência da Computação, o fim do curso de graduação representará o início de sua ascensão social:

[...] eu penso que depois de me formar eu vou trabalhar com pesquisa e ser professor de universidade. Também penso em começar a ganhar dinheiro, juntar meu dinheiro e abrir meu negócio na área. (Gabriel José. Entrevista de Campo, 2018).

Isso é observado nos demais estudantes, como as meninas do curso de Medicina Veterinária:

Com certeza eu acho que vai (mudar a minha vida)! Porque, da minha família, eu vou ser a segunda pessoa que tá na faculdade, a segunda pessoa que vai se formar, e, assim, trabalhar com o que você gosta é essencial para você ser feliz na vida e a faculdade vai me trazer esse conhecimento né?! Claro que o que vai fazer o profissional sou eu, a faculdade me dá o conhecimento necessário para que eu comece a evoluir, mas que vai mudar minha vida vai, com certeza! (Maria da Silva. Entrevista de Campo, 2018).

Com certeza, vai mudar! A minha vida e a vida da minha família também! Acho que sim! E é o que eu quero, de verdade! (Alice Souza. Entrevista de Campo, 2018).

Nessa perspectiva, percebemos que esses estudantes acumularão bens simbólicos produzidos na universidade e que poderão influenciar o seu habitus mesmo que possuam um capital cultural fragilizado, acessando um ambiente que antes era exclusivo para poucos, trazendo seu habitus de origem, mas construindo um capital cultural que poderá desestabilizar parte das vigas estruturantes da sociedade que sempre foi marcada por sua exclusão.

${ }^{8}$ A Grande Recife Consórcio de Transporte Metropolitano é a empresa responsável pelo gerenciamento do transporte por ônibus na Região Metropolitana de Recife. Foi criada a partir da Empresa Metropolitana de Transportes Urbanos de Recife. Educação em Revista|Belo Horizonte|v.36|e225572|2020 
A política de cotas é parte desestruturadora dessa ordem excludente e esses sujeitos serão protagonistas dessa história no contexto do grande desafio de que seu projeto de vida não se restrinja à motivação pela acumulação.

\section{A democratização do acesso ao ensino superior pela política de cotas: o que dizem os estudantes}

Por ser uma política que democratiza o acesso, a política de cotas foi fortemente criticada pela elite e até por membros da academia. Na perspectiva de saber como esses estudantes percebem e vivenciam essa política, as entrevistas revelaram aspectos que consideram favoráveis e outros desfavoráveis.

Para o estudante de Ciência da Computação, a política de cotas é muito "interessante", pois:

[...] a qualidade de estudo que muitas escolas particulares oferecem é muito superior a que muitas escolas públicas. Por exemplo, eu tenho um colega que estudou comigo até o primeiro ano do ensino médio e conseguiu uma bolsa numa escola particular e, no terceiro ano, essa escola oferecia tudo o que podia pra os alunos conseguirem um bom resultado no Enem. Eles tinham curso, eles tinham várias coisas além da escola normal, além das disciplinas que eles tinham normalmente. (Pedro Alves. Entrevista de Campo, 2018).

Essa entrevista revelou questionamentos acerca do discurso do mérito que, conforme afirma Castro (2014), se revela como sorte que não é oferecida a todos, mas é cobrado dos indivíduos como se assim o fosse.

Nesse sentido, o sucesso ou o fracasso escolar não podem ser explicados pela ótica do mérito. Eles são fruto das condições mais ou menos favoráveis das exigências escolares (NOGUEIRA. NOGUEIRA, 2002).

Outra estudante, do mesmo curso, também acredita que as cotas são necessárias,

[...] tanto as cotas sociais quanto as raciais. $\mathrm{Na}$ real, eu tento entender porque a pessoa é contra a cota? Só consigo entender que alguém é contra a cota porque ela entende que a cota tira a ideia de igualdade, sabe?! Na verdade, é o contrário. É porque a igualdade é partir do mesmo ponto, é você ter a oportunidade de partir do mesmo lugar que pessoas, ter a mesma oportunidade de chegar, de partir do mesmo ponto de partida. A cota é só um empurrãozinho pra tentar fazer isso acontecer que não acontece, mas dá uma ajudinha, tenta fazer isso acontecer. Então eu não tenho nem o que reclamar sobre cota, acho que é totalmente necessária enquanto a gente tiver num mundo que as pessoas não têm a mesma oportunidade de outras, então vai ter que existir cota até lá (Carla Maria. Entrevista de Campo, 2018).

Já para a estudante de Medicina Veterinária, as cotas poderiam ser com um recorte mais social do que racial. Para ela,

[...] deveria juntar as quantidades numa cota só, de renda e racial, que foi o caso da minha que eu entrei. Porque existe o eventual branco e pobre e existe o eventual negro e rico, é difícil essas. É mais comum ver um negro pobre do que um negro rico, né? Mas existem esses eventos! Então, acho que beneficiaria a todos se fosse assim, e, ajuda muito, pois nem todos os meninos da minha comunidade, lá do meu bairro, tiveram oportunidade de fazer o cursinho que eu fiz, né? Então, pra eles seria essencial essas cotas, pra eles pelo menos competirem, porque, no Brasil, é difícil o ensino particular. O particular é muito diferente, é muito superior ao ensino público que a gente tem hoje, não deveria ser assim, mas é! É uma realidade, é um fato. (Alice Souza. Entrevista de Campo, 2018).

Numa perspectiva mais crítica, temos o relato de um estudante de Ciência da Computação que acredita que as cotas são importantes "como uma medida provisória", mas

[...] infelizmente tão sendo usadas como algo pra tapar um buraco que existe na educação do país, então, é aquele tipo de coisa: como está agora precisa ter, mas o ideal era que o sistema 
fosse ajeitado e que em breve não fossem mais necessárias. (Pedro Alves. Entrevista de Campo, 2018).

Já a estudante de Medicina Veterinária acredita que as cotas são “injustas”, pois, para ela:

[...] uma pessoa sai mais favorecida que a outra, porque às vezes você tira a mesma nota. Uma pessoa que estudou comigo, da mesma sala que eu, e aí eu tirei uma nota maior no ENEM e ela tirou menor do que eu, mas ela, por ser negra, passa na minha frente, sabe? Aí eu acho isso meio injusto, mas, assim, é bom que favorece quem tem menos, é menos investimento na educação. Acho que é bom porque, mesmo quem não tem tanto acesso a educação eficiente, tem direito também de entrar na faculdade (Clécia Maria. Entrevista de Campo, 2018).

Essas visões revelaram que os jovens beneficiários da política de cotas para acesso ao ensino superior acreditam que no nosso país há grande disparidade entre o ensino particular e o ensino público, favorecendo a exclusão de jovens das escolas públicas no ensino superior, e que as cotas possibilitam diminuir a desigualdade experimentada por quem não é detentor do capital cultural valorizado pela sociedade, nem de capital social e econômico.

Democratizar o acesso à universidade pública é uma tentativa de enfrentar os processos de exclusão social. Para Melo, Campos e Zarias (2015), essa exclusão está incorporada pelos próprios excluídos e exige uma mudança em todo o processo de escolarização a fim de superar o habitus internalizado pelos jovens oriundos de escolas públicas.

O diploma universitário, como afirmam Melo, Campos e Zarias (2015), tem um valor simbólico e é capaz de promover a diferenciação social.

\section{O diploma universitário: limites e desafios do letramento acadêmico}

Os desafios do ingresso no ensino superior não findam no momento da matrícula no curso desejado. Essa é a primeira porta que se abre, mas, como afirma Castro (2014), há tantas outras a serem abertas, inclusive que possibilitem a permanência neste nível de ensino.

O letramento é uma delas, pois, como afirmam Lea e Street (2014), o letramento acadêmico está enraizado nas relações de poder e na autoridade conferida ao campo, produzindo sentido e identidade. Para esses estudantes, é preciso garantir a adaptação às práticas acadêmicas prestigiadas e consolidadas que, supostamente, são conhecidas e compartilhadas por todos, mas que não são de conhecimento desses grupos (JUCHUM, 2016).

Como nos revelam os relatos, os estudantes pesquisados tiveram que superar a defasagem escolar:

[...] eu achei um pouco diferente da escola, não tava muito acostumado com o ritmo de estudos que eu precisava ter aqui. Assim, é porque tem duas disciplinas que a gente vai pro laboratório é: Introdução a Ciência da Computação, de vez em quando a gente vai pro laboratório; e Introdução a Programação, todas as aulas são no laboratório. Mas as outras são em sala de aula, que é Cálculo, Álgebra e Matemática discreta. Consegui conciliar um tempo de estudo. $\mathrm{Eu}$, quando chego em casa, todo dia, eu sento e reviso já o que eu vi aqui na faculdade e de manhã também termino de tomar café e pego o caderno e vou resolver alguns exercícios. (Gabriel José. Entrevista de campo, 2018).

Aí eu faço estágio de manhã, estágio no hospital veterinário aqui da Rural (UFRPE). Aí eu faço estágio de manhã, de tarde tô na aula e de noite eu fico na biblioteca estudando. Aí durmo e volto pro estágio. (João Costa. Entrevista de campo, 2018).

É bem puxado. É bem mais puxado do qualquer coisa que eu tenha feito na minha vida. Quando eu chego em casa, eu chego muito cansado, mas eu tenho que estudar, né? Principalmente Anatomia, que acredito ser a matéria mais difícil agora do primeiro período. E eu tenho que estudar e assim tá sendo muito puxado mesmo. Não tenho base e tenho que correr atrás. (Bruno Gomes. Entrevista de campo, 2018). 
[...] quando eu terminei o ensino médio eu não sabia muita coisa. Para você ter noção, eu não sabia nem o que era diluir e dissolver. Eu não sabia a diferença, pra mim era tudo a mesma coisa. (Clécia Maria. Entrevista de campo, 2018).

A necessidade de criar uma rotina de estudo, de entender o funcionamento da universidade e de superar as dificuldades do letramento, principalmente o matemático, no ensino médio, marcam as falas dos estudantes. Porém, isso não se configura como um obstáculo, mas como um desafio a ser superado em nome do sonho de um futuro melhor.

\section{CONSIDERAÇÕES FINAIS}

A proposta deste artigo consistiu em realizar uma reflexão acerca do sistema escolar, especialmente do ensino superior, como um campo de representações simbólicas que recebe, atualmente, estudantes antes alijados, como consequência da política de cotas para ingresso nas universidades públicas federais, desestabilizando a lógica excludente que foi imposta pela colonialidade.

A trajetória escolar e acadêmica dos estudantes cotistas é resultante do capital cultural acumulado, que será também influenciado pelos novos códigos próprios da academia, que terão que construir no seu percurso acadêmico, modificando indelevelmente seus percursos pessoais e sociais.

A universidade, como instituição legitimadora de lugares sociais, é feita de códigos acadêmicos e sociais dominantes. Em que pese o ingresso possibilitado pela política de cotas, a permanência depende de processos de adaptação dos estudantes, desconsiderando-se o ponto de partida de cada um.

Esse ponto de partida reflete e é refletido no/pelo habitus. Conhecer as histórias de vida e suas estratégias de superação para construção do letramento acadêmico, constitui-se como condição para sua permanência e permite um olhar que vai muito além da implementação de uma política pública específica, apesar de toda sua importância. Aponta para o reconhecimento da pluralidade das identidades sociais e para a contribuição da universidade para a construção de uma sociedade com igualdade de oportunidades e desestruturadora da lógica colonial que inclui "berço e sobrenome" e exclui a grande maioria.

\section{REFERÊNCIAS}

BELLETATI, Valéria Cordeiro Fernandes. Dificuldades de alunos ingressantes na universidade pública: indicadores para reflexão sobre a docência universitária. 2011. 237 f. Tese (Doutorado em Educação) - Programa de Pós-Graduação em Educação, Faculdade de Educação, Universidade de São Paulo, São Paulo, 2011.

BOBBIO, Norberto; MATTEUCCI, Nicola; PASQUINO, Gianfranco. Dicionário de Política. Brasília: Editora Universidade de Brasília, 2010.

BOURDIEU, Pierre. A economia das trocas simbólicas. São Paulo: Perspectiva, 1999.

BOURDIEU, Pierre. A distinção: crítica social do julgamento. São Paulo: Edusp, 2008.

BOURDIEU, Pierre; CHARTIER, Roger. O sociólogo e o historiador. Belo Horizonte: Autêntica Editora, 2011.

BOURDIEU, Pierre; PASSERON, Jean-Claude. A reprodução: elementos para uma teoria do sistema de ensino. Rio de Janeiro: Francisco Alves Editora S/A, 1992. 
CASTRO, Michele Doris. Estudantes cotistas do Rio Grande do Sul encontram seu lugar na UFRGS? 2014. 89 f. Dissertação (Mestrado em Educação) - Programa de Pós-Graduação em Educação, Faculdade de Educação, Universidade Federal do Rio Grande do Sul, Porto Alegre, 2014.

CASTRO-GÓMEZ, Santiago. La hybris del punto cero: ciencia, raza e ilustración en la Nueva Granada (1750-1816). Bogotá: Editorial Pontificia Universidad Javeriana, 2005.

CAVALCANTE, Cláudia Valente. Políticas de ação afirmativa na educação superior brasileira: uma análise dos planos nacionais de educação 2001-2010 e 2014-2024: uma estratégia para a redução das desigualdades sociais e escolares?. POIÉSIS - Revista do Programa de Pós-graduação em Educação, Unisul/Tubarão, v. 9, n. 16, p. 333-350, jul/dez 2015.

JUCHUM, Maristela. Letramentos Acadêmicos: projetos de trabalho na universidade. 2016. 170 f. Tese (Doutorado em Letras) - Programa de Pós-Graduação em Letras, Universidade Federal do Rio Grande do Sul, Porto Alegre, 2016.

MELO, Patrícia Bandeira de; CAMPOS, Luís Henrique Romani; ZARIAS, Alexandre. O novo babitus de estudantes da universidade pública no interior do nordeste, Opinião, Rio de Janeiro. FLACSO Brasil, n. 18, p. 01-13, nov. 2015.

NOGUEIRA. Cláudio Marques Martins; NOGUEIRA, Maria Alice. A sociologia da educação de Pierre Bourdieu: limites e contribuições. Educação \& Sociedade, Campinas, ano XXIII, n. 78, p. 1535, Abril 2002. Disponível em: < www.scielo.br/pdf/es/v23n78/a03v2378>. Acesso em: 20 mar. 2018.

NOVAES, Daniele Rego; VARGAS, Hustana Maria. Critérios de ingresso no ensino superior pela via da reserva de vagas: uma discussão sob a lente das engenharias. POIÉSIS - Revista do Programa de Pós-Graduação em Educação, Unisul/ Tubarão, v.9, n.16, p. 313 - 332, jul/dez 2015.

PINHEIRO, Carlos Henrique Lopes. Difusão Territorial e Dinâmica Socioespacial da Educação Superior no Estado do Ceará. XV Congresso Brasileiro de Sociologia: 2018. Disponível em: < http://repositorio.ufc.br/bitstream/riufc/52363/1/2011_eve_chlpinheiro.pdf >. Acesso em: 25 abr. 2018.

QUIJANO, Aníbal. A colonialidade do saber: eurocentrismo e ciências sociais. Perspectivas latinoamericanas. Buenos Aires: CLACSO, Consejo Latinoamericano de Ciencias Sociales, 2005. Disponível em: < http://biblioteca.clacso.edu.ar/clacso/sur-sur/20100624103322/12_Quijano.pdf>. Acesso em: 18 nov. 2018.

QUiJANO, Aníbal. Colonialidade, poder, globalização e democracia. Revista Novos Rumos, São Paulo, a. 17, n. 37, p. 4-28, 2002. Disponível em:

<http://www.educadores.diaadia.pr.gov.br/arquivos/File/2010/veiculos_de_comunicacao/NOR/N OR0237/NOR0237_02.PDF>. Acesso em: 28 jan. 2019.

SOUZA, Liliane Pereira de. A Violência Simbólica na Escola: Contribuições de Sociólogos Franceses ao Fenômeno da Violência Escolar Brasileira. Revista Labor, Fortaleza, v.1, n. 7, p. 20-34, 2012.

Disponível em:

<http://www.revistalabor.ufc.br/Artigo/volume7/2_A_violencia_simbolica_na_escola $>$. Acesso em: 30 mar. 2018. 